\title{
Molecular epidemiology and clinical characteristics of hepatitis delta virus (HDV) infected patients with elevated transaminases in Shanghai, China
}

Shanshan $\mathrm{Wu}^{\dagger}$, Yi Zhang ${ }^{\dagger}$, Yuyan Tang, Ting Yao, Mengjiao Lv, Zhenghao Tang, Guoqing Zang, Yongsheng $\mathrm{Yu}^{*}$ and Xiaohua Chen ${ }^{*}$ (iD

\begin{abstract}
Background: Patients coinfected with HBV and hepatitis D virus (HDV) have a greater risk of HCC and cirrhosis. The current study was undertaken to assess HDV genotype distribution and determine clinical characteristics of hepatitis delta virus (HDV) among HBsAg positive individuals in Shanghai.

Method: This retrospective study involved 225 serum samples from HBsAg positive hospitalized patients from October 2010 to April 2013. HDV-specific RT-nested PCR was used to amplify HDV RNA. HDV genotypes were characterized by Next-generation sequencing (NGS), followed by phylogenetic analyses. HDV/HBV co-infected patients and HBV mono-infected patients were compared clinically and virologically.

Results: Out of the $225 \mathrm{HBsAg-positive} \mathrm{serum} \mathrm{samples} \mathrm{with} \mathrm{elevated} \mathrm{transaminases,} \mathrm{HDV-RNA} \mathrm{was} \mathrm{identified} \mathrm{in} 11$ (4.9\%) patients. The HBV loads in the HDV positive group were significantly lower than the HDV negative HBVinfected patients. The aminotransferase enzymes were significantly higher in HDV/HBV co-infected compared to HDV negative patients $(P<0.05)$. Phylogenetic analyses indicated that HDV-2 genotype being the predominant genotype, other HDV genotypes were not observed. HDV/HBV patients were significantly associated with a rather unfavourable clinical outcome.
\end{abstract}

Conclusion: In summary, the prevalence of HDV infection in patients with elevated transaminases is not low and the predominance of HDV genotype 2 infection in Shanghai. This finding helps us to better understand the correlation of HDV/HBV co-infection. Moreover, Next-generation sequencing (NGS) technologies provide a rapid, precise method for generating HDV genomes to define infecting genotypes.

Keywords: Hepatitis Delta virus, Genotype distribution, Next-generation sequencing, RT-nested PCR

\footnotetext{
* Correspondence: yuyongshengsyy@163.com; chenxiaohua2000@163.com

'Shanshan Wu and Yi Zhang contributed equally to this work and

considered co-first authors.

Department of Infectious Diseases, Shanghai Jiao Tong University Affiliated

Sixth People's Hospital, Shanghai 200233, China
}

(c) The Author(s). 2020 Open Access This article is licensed under a Creative Commons Attribution 4.0 International License, which permits use, sharing, adaptation, distribution and reproduction in any medium or format, as long as you give appropriate credit to the original author(s) and the source, provide a link to the Creative Commons licence, and indicate if changes were made. The images or other third party material in this article are included in the article's Creative Commons licence, unless indicated otherwise in a credit line to the material. If material is not included in the article's Creative Commons licence and your intended use is not permitted by statutory regulation or exceeds the permitted use, you will need to obtain permission directly from the copyright holder. To view a copy of this licence, visit http://creativecommons.org/licenses/by/4.0/ The Creative Commons Public Domain Dedication waiver (http://creativecommons.org/publicdomain/zero/1.0/) applies to the data made available in this article, unless otherwise stated in a credit line to the data. 


\section{Background}

More than 240 million people throughout the world are chronically infected with hepatitis B virus (HBV), and approximately 15-25 million are co-infected with hepatitis D virus (HDV), a satellite virus which requires $\mathrm{HBV}$ envelope proteins for particle assembly and spread [1]. The HDV virions possess an outer layer containing hepatitis B surface antigens ( $\mathrm{HBsAg}$ ) and host lipid surrounding the inner nucleocapsid that consists of viral RNA. Thus, HDV depends on HBV for its propagation and replication. Moreover, HBV/HDV co-infection leads to the most severe form of viral hepatitis with an accelerated progression to liver fibrosis, cirrhosis and hepatocellular carcinoma.

In some regions of the world with vaccination campaigns against HBV, the prevalence of HDV infection has significantly declined. However, prevalence of HDV infection is higher in areas where HBV infection is endemic, as well as the central Europe because of the immigrant population regions. HDV Genotype 1 is present globally, whereas other HDV genotypes occur in specific geographical regions. Genotype 2 (previously 2a) prevails in Japan, Taiwan and Russia [2,3]. Genotype 3 which is the most diverged one is exclusively found in Amazon Basin [4]. HDV-4 (previously 2b) is found in Japan and Taiwan, whereas genotypes 5-8 are described in individuals of African origin [5]. China is one of the countries with the highest number of hepatitis $\mathrm{B}$ virus infections in the world, however, no nationwide cohort study has been conducted to assess the prevalence of HDV infection.

Usually, the HDV prevalence is commonly described as percentage of anti-HDAg positive individuals in HBsAg-positive patients using commercial ELISA kits. Anti-HDV seropositive specimens still need to be tested for serum HDV RNA. Several commercial anti-HDV tests were used as methods of simultaneous competitive assays. Recently, quantitative microarray antibody capture (Q-MAC) assay was shown closely related with the presence of HDV-RNA (sensitivity, 100\%; specificity, 94.3\% for Q-MAC assay) [6]. Anti-HDV IgG is the most commonly used tool to screen patients with $\mathrm{CHB}$ for concomitant HDV infection or previous infection. Thus HDV RNA is the "gold standard" for the current diagnosis of HDV infection. Quantitative determination of HDV RNA can be used to monitor the response of antiviral therapy and to determine HDV genotype by sequencing HDV RNA positive samples. There is no standard commercial PCR method, which brings great challenges to diagnosis of HDV infection.

Cloning of PCR products and subsequent Sanger dideoxy sequencing technique have been widely used for the genetic analysis, especially in estimating viral populations. However, the two sequencing methods are time- consuming and laborious. Furthermore, preferential selection of deficient viral genomes can bias the results of molecular cloning. Next-generation sequencing (NGS) method had made it possible to generate hundreds of thousands of clonal sequence reads, which provided the potential to reduce the time and complexity for DNA sequencing without the need for cloning. Furthermore, NGS can character genetic diversity with enhanced sensitivity, efficiency, and accuracy.

HBV infection remains a major public health problem in China, with $10-15 \%$ of the population being $\mathrm{HBsAg}$ positive. Molecular epidemiological studies of HDV prevalence and HDV genotypes in HBV endemic areas in China are needed to assess and improve control measures for HBV/HDV co-infection. Therefore, in the study, we investigated the molecular epidemiology and clinical characteristics of HDV infected patients in Shanghai.

\section{Methods \\ Patients}

A total of 225 serum samples with positive HBsAg and HBV DNA were collected from patients in Shanghai Jiao Tong University Affiliated Sixth People's Hospital from October 2010 to April 2013. All patients were seronegative for HCV and HIV antibodies. Patients with other liver disease (drug induced, alcoholic, autoimmune, metabolic) were excluded by serological tests and detailed anamnesis. They had not received any antiviral or immunomodulatory treatment in the preceding 6 months. Anti-HDV IgG was detected by enzyme-linked immunosorbent assay kit (Beijing Beier Biological Engineering Co., Ltd., China). Serum or plasma samples were collected from those patients' blood and used for biochemical and other laboratory routine procedures. Samples were stored at $-80^{\circ} \mathrm{C}$. Demographic and laboratory data were obtained from the Electronic Medical Record (EMR). All patients were not treated with drugs and did not progress to liver cancer. Ethical approval was obtained from the Human Ethics Committee of Shanghai Jiao Tong University Affiliated Sixth People's Hospital (No.2016-73).

\section{Extraction of HDV RNA and first complementary DNA (cDNA) synthesis}

Nucleic acid was extracted from $100 \mu \mathrm{L}$ serum sample using TaKaRa MiniBEST Viral RNA/DNA Extraction Kit (TaKaRa) according to the manufacturer's instructions and was kept at $-80^{\circ} \mathrm{C}$ until further use. About 50 ng of the extracted RNA was reverse transcribed into cDNA using Superscript III reverse transcriptase (Invitrogen) following the manufacturer's instructions. 


\section{Molecular detection and genotyping of HDV}

The HDV-specific nested polymerase chain reaction (PCR) was carried out with first cDNA samples as template to amplify the HDV delta-gene fragment, which included the HDAg open reading frame (ORF) editing site. Briefly, cDNA was amplified in the first PCR reaction using the HDV-specific primers of PCR forward primer and the reverse primer. The specific primers were synthesized as described in reference [7]. The first primer pairs used were HDV850 (5' - CGG ATG CCC AGG TCG GAC C-3') and HDV1380 (5'- GGA GCW CCC CCG GCG AAG A-3'). The second primer pairs used were HDV-887 (5'-GAG ATG CCA TGC CGA CCC GAA GAG-3') and HDV-1290 (5'-GAA GGA AGG CCC TCG AGA ACA AGA-3'). First round PCR amplification was employed in a PCR reaction tube volume of $50 \mu \mathrm{l}$ containing $10 \mathrm{mM}$ concentration of each of the four deoxynucleotides, $10 \mathrm{uM}$ of each outer sense nucleotides and outer anti-sense primers; and 0.5 ul HighFidelity DNA Polymerases and $2 \mathrm{ul}$ cDNA. In the thermal cycler, firstly the samples were incubated on $98^{\circ} \mathrm{C}$ for $2 \mathrm{~min}$ then it was followed by 35 cycles consisting of $98^{\circ} \mathrm{C}$ for $10 \mathrm{~s}, 65^{\circ} \mathrm{C}$ for $30 \mathrm{~s}$ and $72^{\circ} \mathrm{C}$ for $15 \mathrm{~s}$ [2]. We used the negative and positive controls along with samples in each run. Finally nested PCR products $(10 \mu \mathrm{l})$ were electrophoresis on a $1 \%$ agarose gel. All nested PCR products were sequenced by NGS on the illumina miseq system (Illumina Inc.,San Diego, CA, USA) following the manufacturer's protocol. BLAST database (http://blast.ncbi.nlm.nih.gov) to compare input sequence with related reference sequences in the HDV database from the Gene Bank of the National Center for Biotechnology Information (NCBI). Genotypes were assigned by comparing with reference sequences. The HDV sequences were then referenced to the BLAST database (http://blast.ncbi.nlm.nih.gov) to determine the genotype.

\section{Sequence alignments and phylogenetic analyses}

Positive samples were sequenced using an automatic sequencer. Sequences were compiled using the BioEdit program, MEGA7 (molecular evolutionary genetics analysis, version 7.0). The following eight prototype HDVsequences retrieved from the NCBI GenBank were used for alignment and HDV genotyping: (HDV-1: AF098261, AJ000558, AY633627, HM046802,NC001653, KF660600, KF660601, KF660602; HDV-2: KF660599, AF104264, AY261459, MK234594, MK234593; HDV-3: AB037947, AB037948, AB037949; HDV-4: AF018077, AF209859; HDV-5: AM183326, AM183331, JA417551; HDV-6: AJ584847, AM183332; HDV-7: AM183333, JA417541; HDV-8: AM183327, AM183330). The phylogenetic tree reconstruction and the mean value of genetic diversity of DNA sequences were carried out using MEGA 7 software.

\section{Statistical analysis}

All the data was analyzed and the summary statistic was carried out by SPSS version 19.0 (a statistical package). T-test was used to determine the risk factors for acquiring HDV infection. Levels of HBV DNA were expressed

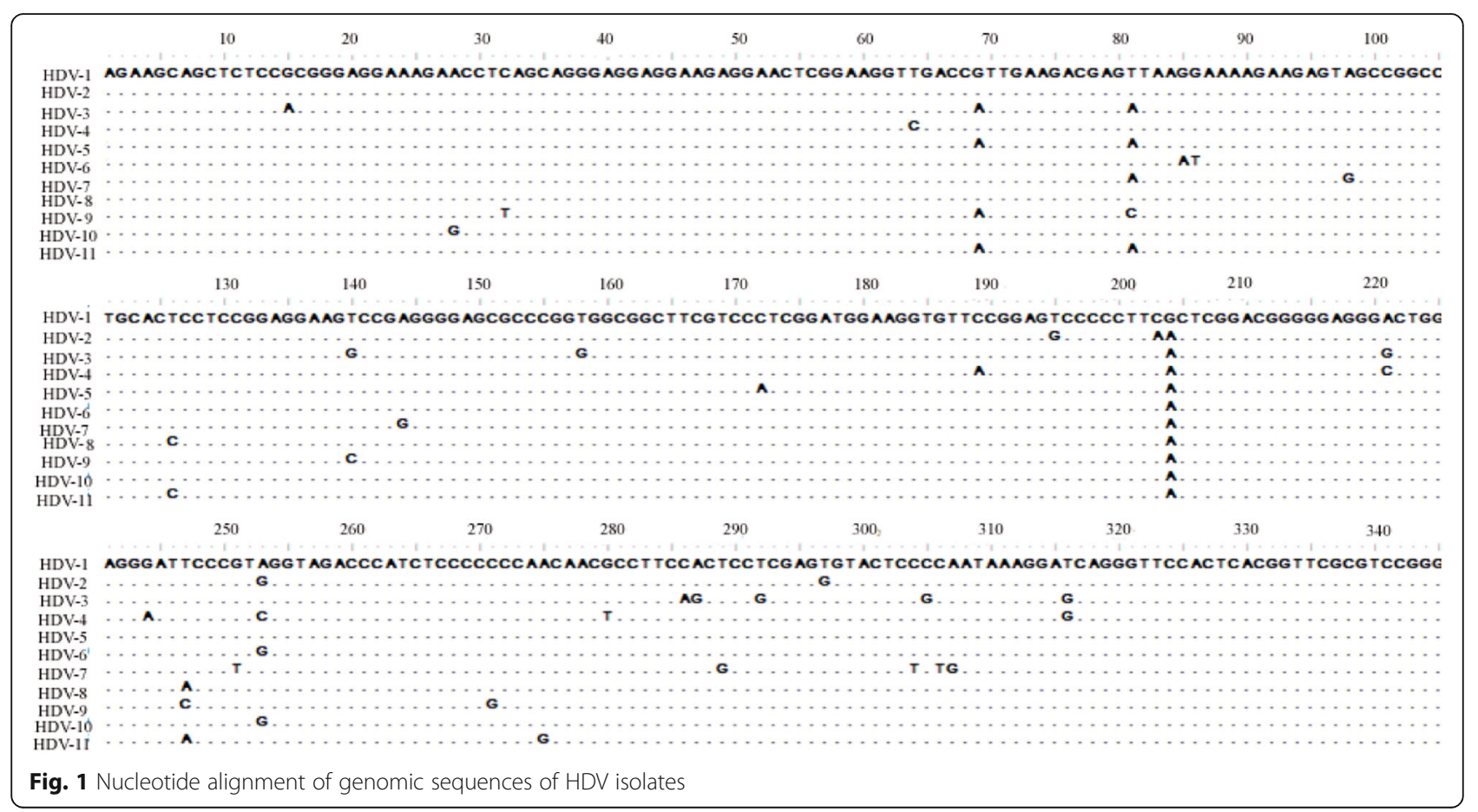


as $\log 10$ copies $/ \mathrm{mL}$. A $P$ value $<0.05$ were considered significant.

\section{Results}

\section{Sample characteristics and HDV prevalence}

Overall, we analyzed clinical characteristics of 225 patients infected with HBV over six months from October 2010 to April 2013, 159 (70.7\%) were females and 66 (29.3\%) were males. Results indicated that median age of mono-HBsAg positive patients and HDV-RNA/HBsAgpositive patients were $41.4 \pm 13$ years and $45.5 \pm 14.9$ years, respectively $(P<0.05)$. None of the HDV-RNA positive samples was anti-HDV antibodies positive, even all 11 patients were antibody negative. However, 11 of the $225 \mathrm{HBsAg}$-positive serum samples demonstrated detectable HDV-RNA given a HDV prevalence of $4.9 \%$ in our study, which may contribute to underestimating the burden of HDV infection.
Detection of HDV RNA in HBsAg positive patients by agarose gel electrophoresis

In 225 patients with HBsAg positive, HDV RNA target gene amplification was detected and agar sugar electrophoresis detected 11 cases of HDV RNA positive specimens. Partial nested PCR products (403 bp) were displayed on agarose gel.

\section{Distribution of HDV genotypes}

To determine HDV genotype in Shanghai, we obtained sequence data of HDV RNA-positive samples via amplifying the HDV delta-gene fragment (L-HDAg region) using automatic sequencer. All of the sequences obtained were compiled using BioEdit, CLUSTX. Distribution of HDV genotypes based on phylogenetic analysis is shown in Fig. 1 and Fig. 2. Phylogenetic analysis was performed using sequences of the HDV amplicons and analysis showed that all analyzed HDV genotypes belong to HDV-2 strain.

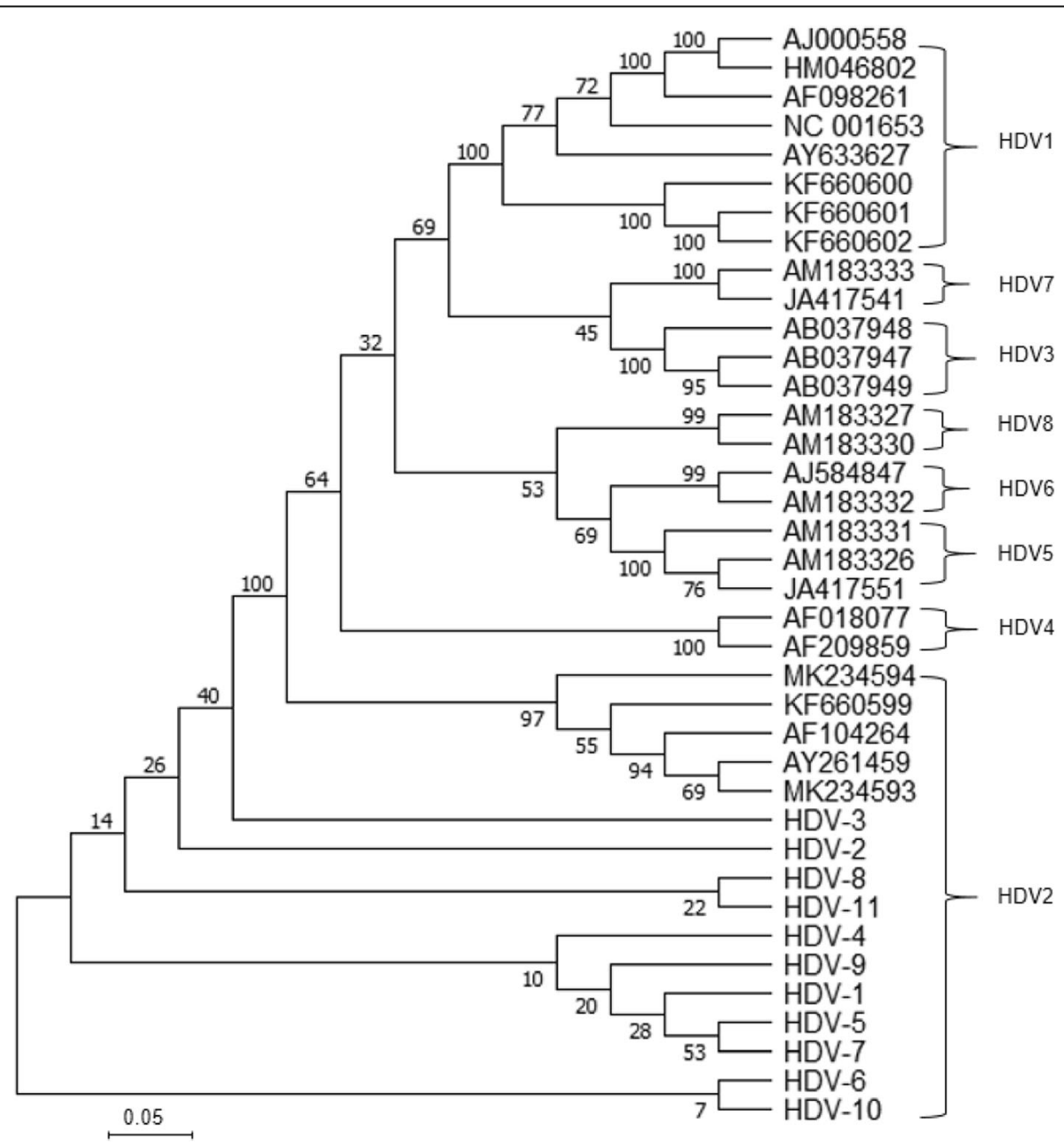

Fig. 2 Phylogenetic analysis based on HDV delta-gene sequences. The horizontal branch was drawn in accord with the relative genetic distance. A number of commonly used reference delta-gene sequences for classifying HDV genotypes were also included and are indicated by accession numbers 
Other HBV genotypes were not detected in this study population. The HDV strains were also clustered in the Asian clade.

\section{HDV and chronic HBV infection clinical outcomes}

The clinical and subclinical characteristics of the patients with or without HDV infection were presented in Table 1. The HBV DNA loads in the HBV/HDV coinfected group were significantly lower in comparison to the HDV negative group (3.85 $\log 10$ copies/ $\mathrm{mL}$ vs. $5.16 \log 10$ copies $/ \mathrm{mL}, P<0.05)$. And the aspartate aminotransferase was significantly higher in HDV positive compared to HDV negative HBVinfected patients $(P<0.05)$.

\section{Discussion}

HDV, the defective satellite RNA virus, was first discovered 41 years ago by Mario Rizzetto that can only assemble and propagate in patients with hepatitis $\mathrm{B}$ virus (HBV). Most countries of the Asian-Pacific region are known to be endemic for HBV. Understanding the prevalence of HDV and its genotypes, which are now identified into eight major genotypes, is very important as part of a molecular clue for distribution of HDV.

The distribution of HDV is still present worldwide, and with a higher incidence in Amazonas, Mongolia, Kiribati, and in Asian countries [8]. In China, a large reservoir of HBV infection, testing for HDV is limited and the burden of HDV is likely underestimated. In a study from Taiwan, high-risk populations like human immunodeficiency virus (HIV) infection and injection drug users (IDUs) had higher prevalence of HDV infection, contrasting with the HBsAg positive subjects [2]. Our research is the first one to describe the molecular epidemiology of HDV in Shanghai, a city of mainland China,

Table 1 Clinical characteristics of the HBsAg positive patients

\begin{tabular}{llll}
\hline characteristics & $\begin{array}{l}\text { HDV/HBV } \\
(n=11)\end{array}$ & $\begin{array}{l}\text { HBV } \\
(n=214)\end{array}$ & P value \\
\hline Age $(y r)$ & $45.45 \pm 14.94$ & $41.39 \pm 13.01$ & .026 \\
Male:Female & $6 / 5$ & $60 / 154$ & .885 \\
ALT(IU/l) & $1485.65 \pm 935.53$ & $768.58 \pm 824.03$ & .006 \\
AST (IU/l) & $977.56 \pm 939.71$ & $424.29 \pm 474.41$ & .000 \\
HBV-DNA (log10 copies/mL) & 3.852 .11 & $5.16 \pm 2.00$ & .038 \\
TBIL ( $\mu$ mol/L) & $80.71 \pm 68.13$ & $64.36 \pm 87.19$ & .942 \\
DBIL $(\mu \mathrm{mol} / \mathrm{L})$ & $73.07 \pm 71.03$ & $43.52 \pm 63.15$ & .446 \\
AKP(U/L) & $151.30 \pm 66.58$ & $114,01 \pm 63.52$ & .442 \\
Y-GT(U/L) & $196.34 \pm 119.76$ & $144.93 \pm 122.32$ & .064 \\
\hline
\end{tabular}

IU international unit; data are given as median with range, $A L T$ alanine aminotransferase, AST aspartate aminotransferase, TBIL total bilirubin, DBIL direct bilirubin, AKP alkaline phosphatase, $\gamma$-GT $\gamma$-glutamyl-transferase. $P$ values are presented for comparisons between HBV-HDV positivity vs. HBV monopositivity which is a very important study as it describes the HBV/ HDV co-infection using molecular methods. Our study showed that the epidemiology of HDV infection among the HBsAg positive subjects from Shanghai area remained low in this study (4.9\%). HDV-1, HDV-2 and HDV-4 are found in China [9]. Surprisingly, our current study showed HDV-2 is the predominant distribution of HDV genotype. However, larger sample size and wider area studies are needed to confirm this distribution of HDV genotype in China.

Several studies had shown that HBV/HDV coinfection could suppress HBV replication with lower levels of HBV viraemia seen in patients positive with HBsAg. In line with mentioned studies, our results indicated that the levels of HBV-DNA were suppressed in patients with HBV/HDV co-infection, suggesting inhibitory effects of HDV on HBV. The potential virological mechanism of inhibition HBV by HDV may be HDV proteins p24 and p27 inhibitor HBV enhancer [10]. Importantly, higher ALT/AST levels in HBV/HDV coinfection patients were detected in our study, which indicated an increased liver damage.

A limitation of our study is that we don't have sufficient patients. We collected only 225 serum samples for HDV RNA detection and all samples were tested for anti-HDV IgG antibodies. It can be hypothesized that the current commercial ELISA kits have insufficient sensitivity and result in a low detection rate of antibodies. Repeated testing could improve the detection rate of the virus, however RNA is easy to degrade and therefore reduces HDV detection rate. So it's very difficult to get accurate data of HDV infection rate without a reliable detection method. Meanwhile, our present study of the prevalence of HDV infection mainly focusing on Shanghai area might not be representative for whole China. However, slight variations can significantly modify the national data. Our study provides new insights into the prevalence and genotype distribution in Shanghai. Moreover, further studies are needed to understand the molecular epidemiology of HDV in different areas in China.

\section{Conclusions}

In conclusion, our study showed that the prevalence of HDV infection in patients with elevated transaminases is not low and the predominance of HDV genotype 2 infection in Shanghai. This finding also helps us to better understand the correlation of HBV/HDV co-infection.

\section{Abbreviations}

HDV: Hepatitis D virus; HBV: Hepatitis B virus; ALT: Alanine aminotransfease; AST: Aspartate transaminase; PCR: Polymerase chain reaction; HIV: Human immunodeficiency virus; HCC: Hepatocellular carcinoma; NGS: Next generation sequencing; IUD: Injection drug users; HBsAg: Hepatitis B surface antigen; DBIL: Direct bilirubin; AKP: Alkaline phosphatase; $\gamma$-GT: $\gamma$-glutamyltransferase 


\section{Acknowledgements}

Authors acknowledge Foundation of Shanghai Municipal Commission of Health and Family Planning and National Natural Science Foundation of China for financial support.

\section{Authors' contributions}

$S W, Y Z, Y Y$, and $X C$ designed the study. SW and $Y Z$ collected and analyzed data. $Y T, T Y, M L, Z T$, and $G Z$ interpreted the results. SW primarily wrote the manuscript. $Y Y, X C, Z T$, and $G Z$ provided valuable insight for revising the manuscript. All authors read and approved the final manuscript.

\section{Funding}

This work was supported by Shanghai Municipal Commission of Health and Family Planning (No. 201640283) and National Natural Science Foundation of China (No. 81770589).

\section{Availability of data and materials}

The datasets generated and/or analyzed during the current study may be made available from the corresponding authors on reasonable request.

\section{Ethics approval and consent to participate}

This study has been ethically approved by the Human Ethics Committee of Shanghai Jiao Tong University Affiliated Sixth People's Hospital (No.2016-73). The given ethics committee waived the need for written consent since all the samples used were collected during the course of routine medical care based on clinicians' request.

\section{Consent for publication}

Not applicable.

\section{Competing interests}

The authors declare that they have no competing interests.

Received: 12 December 2019 Accepted: 20 July 2020

Published online: 03 August 2020

\section{References}

1. Sarah A Hughes, Heiner Wedemeyer, Phillip M Harrison. Hepatitis delta virus. Lancet. 2011; 378(9785):73-85.

2. Lin H-H, Lee SS-J, Yu M-L, Chang T-T, Chien-Wei S, Hu B-S, Chen Y-S, Huang C-K, Lai C-H, Lin J-N, et al. Changing hepatitis D virus epidemiology in a hepatitis $B$ virus endemic area with a national vaccination program. Hepatology. 2015;61(6):1870-9.

3. Ivaniushina V, Radjef N, Alexeeva M, Gault E, Semenov S, Salhi M, Kiselev O, Dény $P$. Hepatitis delta virus genotypes I and II cocirculate in an endemic area of Yakutia. Russia J Gen Virol. 2001:82(Pt 11):2709-18.

4. Alvarado-Mora MV, Romano CM, Gomes-Gouvea MS, Gutierrez MF, Carrilho FJ, Pinho JR. Dynamics of hepatitis D (delta) virus genotype 3 in the Amazon region of South America. Infect Genet Evol. 2011;11(6):1462-8.

5. Le Gal F, Gault E, Ripault M-P, Serpaggi J, Trinchet J-C, Gordien E, Dény P. Eighth major clade for hepatitis delta virus. Emerg Infect Dis. 2006;12(9): 1447-50.

6. Chen X, Oidovsambuu O, Liu P, Grosely R, Elazar M, Winn VD, Fram B, Boa Z, Dai H, Dashtseren B, et al. A novel quantitative microarray antibody capture assay identifies an extremely high hepatitis delta virus prevalence among hepatitis B virus-infected mongolians. Hepatology. 2017;66(6):1739-49.

7. Shih HH, Jeng K-S, Syu W-J, Huang Y-H, Chien-Wei S, Peng W-L, Sheen I-J, Wu J-C. Hepatitis B surface antigen levels and sequences of natural hepatitis $B$ virus variants influence the assembly and secretion of hepatitis $D$ virus. J Virol. 2008;82(5):2250-64

8. Rizzetto M, Ponzetto A, Forzani. Hepatitis delta virus as a global health problem. Vaccine. Vaccine. 1990; 8 Suppl: S10-14.

9. Lin CC, Lee CC, Lin SH, Huang PJ, Li HP, Chang YS, Tang P, Chao M. RNA recombination in hepatitis delta virus: identification of a novel naturally occurring recombinant. J Microbiol Immunol Infect. 2017;50(6):771-80.

10. Heidrich B, Serrano BC, Idilman R, Kabaçam G, Bremer B, Raupach R, Önder FO, Deterding K, Zacher BJ, Taranta A, et al. HBeAg-positive hepatitis delta: virological patterns and clinical long-term outcome. Liver Int. 2012;32(9): $1415-25$.

\section{Publisher's Note}

Springer Nature remains neutral with regard to jurisdictional claims in published maps and institutional affiliations.

\section{Ready to submit your research? Choose BMC and benefit from:}

- fast, convenient online submission

- thorough peer review by experienced researchers in your field

- rapid publication on acceptance

- support for research data, including large and complex data types

- gold Open Access which fosters wider collaboration and increased citations

- maximum visibility for your research: over $100 \mathrm{M}$ website views per year

At BMC, research is always in progress.

Learn more biomedcentral.com/submissions 